\title{
Fast economic indicators
}

\author{
Andy Haldane ${ }^{凶}$ and Shiv Chowla ${ }^{凶}$ \\ Faced with an economic crisis as large and rapid as that precipitated by the COVID-19 \\ pandemic, economists have turned to new 'fast indicators' based on big data, as Andy Haldane \\ and Shiv Chowla of the Bank of England explain.
}

The COVID-19 pandemic has generated a collapse in activity without recent historical precedent: in the UK, gross domestic product (GDP) has fallen by $\sim 25 \%$. It is significant that this collapse occurred almost overnight as lockdown was imposed. How can those who set policies measure this rapid change and track how policies are performing? GDP is estimated quarterly, with a significant lag; other indicators, including surveys such as the Purchasing Managers' Index, average over many respondents and cannot capture the depth of the crisis (BOX 1). Faced with these shortcomings in a fast-moving economy, economists and policymakers have developed a raft of new 'fast indicators' when tracking the economic response to the COVID-19 crisis. These are fast in the sense that they are often available on a daily basis with little, if any, lag. As such, they offer a close to real-time read on how the economy is performing ${ }^{1-3}$.

\section{What the new data sources show}

Data from payments systems (such as debit and credit card transactions) provide a measure of financial flows as agents purchase goods and services. Cash withdrawals from ATMs do likewise. Both provide a close to realtime measure of spending by consumers and corporations. They suggest that aggregate spending fell by $50 \%$ in a matter of weeks during March. They also suggest that, since mid-April, spending has been recovering strongly as lockdown has eased ${ }^{4}$.

Data from Google and Apple have been used to track the mobility of people, as a proxy for their work and shopping-related activities, albeit an imperfect proxy as more work and shopping have moved online. These mobility indices pointed to a $\sim 75 \%$ contraction in consumer retail activity during March and a steady recovery thereafter. Daily information on restaurant bookings, footfall, car, bus, lorry and train journeys and flight departures paint a similar picture.

Data from fintech apps, such as Money Dashboard, have been used to understand how consumers' income and saving have evolved in response to the COVID-19 crisis. At an aggregate level, they confirm a picture of sharp falls in spending, which have since partially reversed. As interesting is the heterogeneity in household behaviour they reveal. The savings of the better-off increased dramatically as their income has been little affected, whereas many poorer households have run down their savings to finance spending in the face of reduced income ${ }^{5}$.

At times of stress, people's sentiment can matter as much as their personal finances. Using semantic algorithmic techniques, the words people use can be filtered to provide metrics of sentiment, such as perceived job security, in close to real time. Indeed, Google searches for the term 'unemployment benefit' have been shown to provide a good leading indicator of actual numbers of people made unemployed. This search rose dramatically during April, well in advance of official labour market data on unemployment.

At a time when statistical agencies have not been able to collect prices using standard survey methods, greater use has been made of data from web scrapes of online sources of spending, allowing close to real-time tracking of consumer price inflation. These data show both the price effects of shortages early on in the crisis - the rise in the price of pasta and paracetamol - and the subsequent depressing effect on prices of the fall in consumer spending.

Fast indicators bring not only greater speed, but also higher granularity. The Bank of England has used realtime payments data to decompose measures of consumer spending into staples (such as food and fuel); work-related (such as travel); delayable spending (such as cars and household goods) and social spending (bars, restaurants, cinemas). Spending in these categories has been markedly different during the crisis, with staples spending remaining stable, delayable spending falling sharply but subsequently recovering fully, whereas social spending has fallen precipitously and only partially recovered.

New surveys and fast indicators also provide a window on how different sectors, regions and demographic groups are affected by the crisis. For example, analysis from the Office for National Statistics and the Resolution Foundation makes clear that the hardest-hit groups are very likely to be the lower-paid and lower-skilled, including young people and women ${ }^{6}$. These groups also tend to have the smallest savings on which to draw to cushion the financial blow.

\section{The future of fast indicators}

These fast indicators have been developed at speed. This means it is unclear, at present, how well they will correlate with official statistics on activity and hence how 


\section{Box 1 | Traditional economic indicators}

Since World War 2, the mainstream measure of economic wellbeing has been gross domestic product (GDP) - the amount of goods and services produced in a country during a certain period of time. National statistical offices across the globe have taken up the challenge of producing GDP statistics. GDP is a useful and durable concept for describing the undulations of economic history, deciding whether an economy is in boom or bust and when judging whether debts are too high or too low.

GDP has a number of limitations. It doesn't speak to issues of inequality, of which the public are becoming increasingly conscious. GDP doesn't always correlate with happiness, especially at high levels of income. And an expansion of GDP may come at the expense of other important things, such as leisure time and the health of the environment.

As a comprehensive measure of economic activity, GDP statistics take time to compile. For example, the US Bureau of Economic Analysis' initial estimate of Q1 US GDP was released at the end of April, with subsequent updates at the end of May and June. In a world of relatively steady economic growth, those delays do not matter much. Monetary and fiscal policy can afford to adjust gradually to smooth out the bumps. However, this luxury does not exist when shocks to the economy are large and it is moving at pace, as during the COVID-19 crisis. Every week of policy inaction might then cost the economy dearly in lost jobs and incomes.

How to bridge the data gap? Until the COVID-19 crisis, the answer often came courtesy of monthly surveys of firms and households. These have grown in prominence since the 2008 global financial crisis as a timely means of revealing how the economy is performing today and how it might evolve tomorrow. It was surveys such as the Purchasing Managers' Index (PMI) that signalled, months ahead of GDP data, that the global economy was in a tailspin in late 2008. However, PMls, which measure the balance of survey respondents, are not well-equipped to capture either the depth or the breadth of the downturn in situations such as the COVID-19 crisis. The same is true of other surveys. or transactions. As with all new sources of data, especially when they are highly granular, there is further to go in making these indicators available publicly, while remaining sensitive to privacy and commercial concerns.

It seems likely that the information in fast indicators will vary over time, with their value highest at times of greatest uncertainty about the economy. These are precisely the times when understanding the economy, and setting policy appropriately in response, is most important. That suggests fast indicators are likely to have an enduring relevance. It also suggests their development represents a significant shift outwards in the technological frontier for monitoring the economy.

In 1923, John Maynard Keynes wrote, "economists set themselves too easy, too useless a task, if in tempestuous seasons they can only tell us, that when the storm is long past, the ocean is flat again" ". Almost a century later, fast indicators are giving economists hope they can make good on Keynes' challenge.

1. Carvalho, V. et al. Tracking the Covid 19 crisis with high-resolution transaction data. Cambridge-INET Institute Working Paper, No: 2020/16 (2020).

2. Chetty, R., Friedman, J., Hendren, N., Stepner, M. \& Opportunity Insights Team. How did Covid-19 and stabilization policies affect spending and employment? A new real-time economic tracker based on private sector data. Opportunity Insights Working Paper, May 2020.

3. Aaronson, D., Brave, S., Butters, R., Sacks, D. \& Seo, B. Using the eye of the storm to predict the wave of Covid-19 UI claims. Federal Reserve Bank of Chicago Working Paper, No. 2020-10 (2020).

4. Haldane, A. The Second Quarter. Bank of England, speech on 30 June 2020.

useful they will prove for nowcasting the present and forecasting the future. Nor, in many cases, are there long back-runs of these series to allow a historical comparison or the development of models of behaviour. This is an important future research agenda, as with any new type of data source.

The fast indicators also raise important issues around transparency. Some of these indicators are based on publicly available data, others use proprietary data and others still contain sensitive data on individual firms
5. Hacioglu, S., Känzig, D. \& Surico, P. Consumption in the time of Covid-19: evidence from UK transaction data. CEPR Discussion Paper DP1 4733 (2020).

6. Gustafsson, M. \& McCurdy, C. Risky business - economic impacts of the coronavirus crisis on different groups of workers. Resolution Foundation, April 2020.

7. Keynes, J. M. A Tract on Monetary Reform (Macmillan, 1923).

\section{Competing interests}

The authors declare no competing interests.

\section{Publisher's note}

Springer Nature remains neutral with regard to jurisdictional claims in published maps and institutional affiliations. 